\title{
Synthesis of the Alkaloid, Xylopinine and the Related Compound by Photo-induced Rearrangement of Spiroisoquinoline
}

\author{
Hiroshi Irie, Kimiko Akagi, Shohei Tani, Keiko Yabusaki, \\ and HIROYUKI YAMANE \\ Faculty of Pharmaceutical Sciences, Kyoto University ${ }^{\mathbf{1}}$
}

(Received September 27, 1972)

\begin{abstract}
Photolysis of 1,2,3,4-tetrahydro-6,7,4',5'-tetramethoxyisoquinoline-1-spiro-2'-indan$1^{\prime}$-one (II) gave 5,6-dihydro-2,3,10,11-tetramethoxyberbinium salt (IV) which was further converted into $2,3,10,11$-tetramethoxyberbine (VI) by treatment with sodium borohydride. In the same reaction sequence, 1,2,3,4-tetrahydro-6,7,5', $6^{\prime}$-tetramethoxyisoquinoline-1spiro-2'-indan-1'-one (IX) was transformed into xylopinire (VII)
\end{abstract}

In the preceding report, ${ }^{2}$ ) we described the synthesis of the alkaloids, rhoeadine and alpinigenine, which was performed by the skeletal rearrangement of spirobenzylisoquinoline into indeno-3-benzazepine. We report here the synthesis of xylopinine, one of the protoberberine alkaloids, starting from the same type of spirobenzylisoquinoline under photo-induced skeletal rearrangement. The dihydroxyspiroisoquinoline $(\mathrm{I})^{2)}$ was methylated with diazomethane in the usual manner to give a mixture of the tetramethoxy-spiroisoquinoline (II) and the N-methylated tertiary base (III), presence of which was proposed from the evidence showing the signal at $\delta 2.30$ as a singlet assigned to $\mathrm{N}$-methyl group in the nuclear magnetic resonance (NMR) spectrum of this mixture. Isolation of II in pure form was accomplished by hydrogenation of the neutral portion obtained from treatment of the mixture with an excess of benzyloxycarbonyl chloride and triethylamine (see experimental part). Irradiation of the spiroisoquinoline (II) with high pressure mercury lamp in dry tetrahydrofuran for $1 \mathrm{hr}$ under nitrogen gave a mixture of the berbinium salt (IV) and the lactam (V) in $80 \%$ and $10 \%$ yield, respectively. Treatment of the salt (IV) with sodium borohydride in ethanol furnished

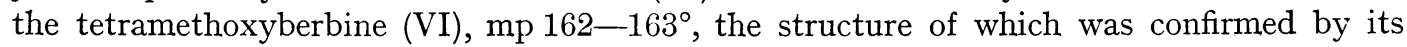
elemental analysis and the spectroscopic properties. The lactam (V), which showed strong carbonyl band at $1640 \mathrm{~cm}^{-1}(\mathrm{KBr})$ in its infrared (IR) spectrum and exhibited the signals of three singlets at $\delta 7.35,7.13$ and 6.75 corresponding to an olefinic proton on $\mathrm{C}-13$ and two protons on aromatic ring A of protoberberine skeleton in its NMR spectrum, was also converted to the same berbine (VI) by treatment with lithium aluminium hydride followed by sodium borohydride.

In order to rationalise the applicability of the photoinduced rearrangement, synthesis of xylopinine (VII) was undertaken. Pictet-Spengler cyclisation of 5,6-dimethoxyindan-1,2dione $^{3)}$ with 3,4-dihydroxyphenethylamine hydrobromide gave the spiroisoquinoline (VIII) in $80 \%$ yield. The hydrochloride of (VIII) was smoothly methylated with diazomethane in methanol to give the tetramethoxy-spiroisoquinoline (IX), mp 200-202 ${ }^{\circ}$, while the free base (VIII) was not subjected to methylation with the same reagent because of its insolubility in the usual organic solvents.

Irradiation of (IX) in the same manner as described in the case of II gave the berbinium salt $(\mathrm{X})$ and the lactam $(\mathrm{XI})$ in $85 \%$ and $8 \%$ yields, respectively. Reduction of the salt (X)

1) Location: Sakyo-ku, Kyoto.

2) H. Irie, S. Tani, and H. Yamane, Chem. Commun., 1970, 1713; idem, J. Chem. Soc. Perkin Transaction I, 1927, 2986.

3) J. Schmutz, Helv. Chim. Acta, 42, 335 (1959). 
with sodium borohydride in ethanol furnished ( \pm )-xylopinine, $\mathrm{mp} 189-190^{\circ}$ which was identical with the authentic specimen of $( \pm)$-xylopinine ${ }^{4)}$ in IR (KBr) and NMR spectra.<smiles>[R20]Oc1cc2c(cc1O[R20])C1(CC2)C(=O)c2cc([R2])c([R])c([R])c2C1=O</smiles>

I $\quad: \mathrm{R}^{1}=\mathrm{R}^{4}=\mathrm{R}^{5}=\mathrm{H}$, $\mathrm{R}^{2}=\mathrm{R}^{3}=\mathrm{OMe}$

II $: \mathrm{R}^{1}=\mathrm{Me}, \mathrm{R}^{4}=\mathrm{R}^{5}=\mathrm{H}$, $\mathrm{R}^{2}=\mathrm{R}^{3}=\mathrm{OMe}$

III $: \mathrm{R}^{1}=\mathrm{R}^{5}=\mathrm{Me}, \mathrm{R}^{4}=\mathrm{H}$, $\mathrm{R}^{2}=\mathrm{R}^{3}=\mathrm{OMe}$

VIII : $\mathrm{R}^{1}=\mathrm{R}^{2}=\mathrm{R}^{5}=\mathrm{H}$, $\mathrm{R}^{3}=\mathrm{R}^{4}=\mathrm{OMe}$

IX : $\mathrm{R}^{1}=\mathrm{Me}, \mathrm{R}^{2}=\mathrm{R}^{5}=\mathrm{H}$, $\mathrm{R}^{3}=\mathrm{R}^{4}=\mathrm{OMe}$

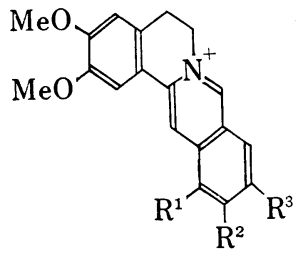<smiles>[R]c1cc2c([R])cc3cc2c(cc3[R])c1[R]</smiles><smiles>[R]c1cc2c(cc1[R])CC1c3cc(OC)c(OC)cc3CCN1CC2</smiles>

IV $: \mathrm{R}^{1}=\mathrm{R}^{2}=\mathrm{OMe}, \mathrm{R}^{3}=\mathrm{H} \quad \mathrm{V}: \mathrm{R}^{1}=\mathrm{R}^{2}=\mathrm{OMe} ; \mathrm{R}^{3}=\mathrm{H} \quad \mathrm{VI}: \mathrm{R}^{1}=\mathrm{R}^{2}=\mathrm{OMe}, \mathrm{R}^{3}=\mathrm{H}$ $\mathrm{X}: \mathrm{R}^{1}=\mathrm{H}, \mathrm{R}^{2}=\mathrm{R}^{3}=$ OMe XI $: \mathrm{R}^{1}=\mathrm{H}, \mathrm{R}^{2}=\mathrm{R}^{3}=\mathrm{OMe}$ VII $: \mathrm{R}^{1}=\mathrm{H}, \mathrm{R}^{2}=\mathrm{R}^{3}=\mathrm{OMe}$

Chart 1

\section{Experimental ${ }^{5)}$}

Methylation of the Spiroisoquinoline (I) — The hydroxy-spiroisoquinoline (I) ${ }^{2)}(1.4 \mathrm{~g})$ was treated with ethereal diazomethane in dry tetrahydrofuran $(200 \mathrm{ml})$ in refrigerator for 3 days. After decomposition of the excess diazomethane with acetic acid, the solution was evaporated to dryness to leave a residue which was taken up in dilute hydrochloric acid. The aqueous solution was washed with ether and basified with aqueous sodium hydroxide and extracted with ether. The ethereal extract was washed with water, dried and evaporated to dryness to give an oily residue $(1.32 \mathrm{~g})$ which was treated with benzyloxycarbonyl chloride $(4 \mathrm{ml})$ and triethylamine $(5 \mathrm{ml})$ in tetrahydrofuran $(40 \mathrm{ml})$ at room temperature for $1.5 \mathrm{hr}$. After removal of triethylamine hydrochloride by filtration, the filtrate was concentrated to dryness to leaves a residue which was taken up in ether. The ethereal solution was washed with dilute hydrochloric acid and water, dried and evaporated. The resulting residue was, without further purification, hydrogenated in ethanol with palladium black as catalyst. The usual work-up gave the spiroisiquinoline (II) (1.08 g), which was characterised as its picrate, $\mathrm{mp} 123-124^{\circ}$. Anal. Calcd. for $\mathrm{C}_{21} \mathrm{H}_{23} \mathrm{O}_{5} \mathrm{~N} \cdot \mathrm{C}_{6} \mathrm{H}_{3} \mathrm{O}_{7} \mathrm{~N}_{3}: \mathrm{C}, 54.18 ; \mathrm{H}, 4.38 ; \mathrm{N}, 9.36$. Found: $\mathrm{C}, 53.78 ; \mathrm{H}, 4.74 ; \mathrm{N}, 9.01$. IR $\nu_{\max }^{\mathrm{KBr}} 1932(\mathrm{~N}+\mathrm{H})$ and $1699(\mathrm{CO}) \mathrm{cm}^{-1} ; \mathrm{NMR} \delta: 7.63$ and 7.03 (AB-type quartet, $J=8 \mathrm{~Hz}, 2$ arH), 6.60 and $6.12(\mathrm{~s}, 2 \mathrm{arH}), 3.97,3.90$, and $3.83(\mathrm{~s}, 4 \mathrm{OMe})$ and $2.13(\mathrm{~s}, \mathrm{NH})$.

Photolysis of 1,2,3,4-Tetrahydro-6,7,4', $5^{\prime}$-tetramethoxyisoquinoline-1-spiro-2'-indan-1'-one (II) - The spirobenzylisoquinoline (II) $(182 \mathrm{mg})$ was irradiated with high pressure mercury lamp in dry tetrahydrofuran $(150 \mathrm{ml})$ under nitrogen for $1 \mathrm{hr}$. The solution was evaporated under reduced pressure to leave a brown oil which was taken up in water. The aqueous solution was washed with ether and concentrated to dryness sodium in vacuo to yield the berbinium salt (IV) $(145 \mathrm{mg})$ which was, without further purification, treated with dryness borohydride $(100 \mathrm{mg})$ in ethanol $(50 \mathrm{ml})$. The usual work-up gave 2,3,11,12-tetramethoxyberbine (VI) $(120 \mathrm{mg}), \mathrm{mp} 162-163^{\circ}$. Anal. Calcd. for $\mathrm{C}_{21} \mathrm{H}_{25} \mathrm{O}_{4} \mathrm{~N} \cdot 1 / 2 \mathrm{H}_{2} \mathrm{O}: \mathrm{C}, 69.21 ; \mathrm{H}, 7.19 ; \mathrm{N}, 3.84$. Found: $\mathrm{C}$, $70.04 ; \mathrm{H}, 7.02 ; \mathrm{N}, 3.80, \mathrm{M}^{+}=355$, NMR $\delta: 6.80(\mathrm{~s}, 3 \mathrm{arH}), 6.62(\mathrm{~s}, \operatorname{arH}), 3.92,3.87$, and $3.82(\mathrm{~s}, 4 \mathrm{OMe})$. The ether washing mentioned above was washed with water, dried and concentrated to dryness to leave the lactam (V) $\left(15 \mathrm{mg}\right.$ ) which crystallized from ethanol, mp 189-190. Anal. Calcd. for $\mathrm{C}_{21} \mathrm{H}_{21} \mathrm{O}_{5} \mathrm{~N}$ : C, 68.65; $\mathrm{H}, 5.76$; $\mathrm{N}, 3.81$. Found: $\mathrm{C}, 68.95 ; \mathrm{H}, 5.72 ; \mathrm{N}, 3.66$. IR $v_{\max }^{\mathrm{KBr}} 1640 \mathrm{~cm}^{-1}(\mathrm{CO})$; NMR $\delta: 8.20$ and 7.10 (ABtype quartet, $J=9 \mathrm{~Hz}, 2 \mathrm{arH}) 7.35,7.13$, and $6.75\left(\mathrm{~s}, 2 \mathrm{arH}\right.$ and $\left.=\mathrm{C}_{13} \mathrm{H}\right), 4.00,3.99$, and $3.97(\mathrm{~s}, 4 \mathrm{OMe})$.

1,2,3,4-Tetrahydro-6,7-dihydroxyisoquinoline-1-spiro-2'-5',6'-dimethoxyindan-1'-one (VIII) - 5,6-Dimethoxyindan-1,2-dione $(10 \mathrm{~g})$ and 3,4-dihydroxyphenethylamine hydrobromide $(10 \mathrm{~g})$ were heated under reflux in ethanol $(300 \mathrm{ml})$ for $4 \mathrm{hr}$. Evaporation of the solvent gave a residue which crystallised from ethanol and the crystals dissolved in water $(200 \mathrm{ml})$ and the aqueous solution was basified with aqueous ammonia

4) M. Tomita, and J. Kunitomo, Yakugaku Zasshi, 80, 1238 (1960); D.W. Brown and S.F. Dyke, Tetrahedron Letters, 1964, 3587.

5) Melting points were determined with a Yanagimoto microscope hot stage apparatus and not corrected. NMR spectra were obtained with a Varian A-60 spectrometer in deuteriochloroform using tetramethylsilane as an internal standard. Mass spectra were determined with a Hitachi RMU-6D mass spectromer. 
to give a precipitate. The precipitate was collected by filtration and crystallized from methanol to give the spiroisoquinoline (VIII) (13 g), mp 228-230 . Anal. Calcd. for $\mathrm{C}_{19} \mathrm{H}_{19} \mathrm{O}_{5} \mathrm{~N} \cdot \mathrm{CH}_{3} \mathrm{OH}: \mathrm{C}, 64.33 ; \mathrm{H}, 6.21$; $\mathrm{N}, 3.75$. Found: C, 64.13; H, 6.09; N, 3.66. IR $v_{\max }^{\mathrm{KBr}} 1710 \mathrm{~cm}^{-1}$ (CO). The hydrochloride of (VIII) was prepared in ethanol with concentrated hydrochloric acid in the usual manner, $\mathrm{mp} 204-205^{\circ}$ (from acetonewater).

Methylation of the Spiroisoquinoline (VIII) — The hydrochloride of VIII (2.5 g) was treated with ethereal diazomethane in methanol $(500 \mathrm{ml})$ with stirring at $0^{\circ}$ for $3 \mathrm{hr}$. After decomposing excess diazomethane with acetic acid, the reaction mixture was concentrated to dryness under reduced pressure to leave a residue which was taken up in chloroform. The organic solution was washed with dilute sodium hydroxide and water, and dried. Removal of the solvent left a residue which crystallised from ethanol to yield the tetramethoxy-spiroisoquinoline (IX) $(1.5 \mathrm{~g}), \mathrm{mp} 202-203^{\circ}$. Anal. Calcd. for $\mathrm{C}_{21} \mathrm{H}_{23} \mathrm{O}_{5} \mathrm{~N}: \mathrm{C}, 68.28 ; \mathrm{H}, 6.28$; $\mathrm{N}, 3.70$. Found: $\mathrm{C}, 68.07 ; \mathrm{H}, 6.36 ; \mathrm{N}, 3.69$. IR $\nu_{\max }^{\mathrm{KBr}} 3250(\mathrm{NH}), 1700$ and $1690 \mathrm{~cm}^{-1}(\mathrm{CO}), \mathrm{NMR} \delta: 7.20$, $6.91,6.60$, and $6.13(\mathrm{~s}, 4 \mathrm{arH}), 3.38\left(\mathrm{~s},-\mathrm{CH}_{2}-\mathrm{Ar}\right), 3.99,3.93,3.83$, and 3.59 (s, $\left.4 \mathrm{OMe}\right)$.

Photolysis of the Tetramethoxy-spiroisoquinoline (IX)—-The tetramethoxy-spiroisoquinoline (IX) $(200 \mathrm{mg})$ was irradiated in the same manner as in II. The solution was evaporated under reduced pressure to leave a brown oil which was taken up in water. The aqueous solution was washed with ethyl acetate and concentrated to dryness in vacuo to yield the berbinium salt (X) (150 mg) which was treated with sodium borohydride $(100 \mathrm{mg})$ in ethanol $(50 \mathrm{ml})$. The usual work-up gave (土)-xylopinine (VII) $(130 \mathrm{mg}), \mathrm{mp} 189$ $190^{\circ}$, which was identical with the authentic sample of $( \pm)$-xylopinine in mixed melting point, IR and NMR spectra. The ethyl acetate washings mentioned above was washed with water, dried and concentrated to dryness to leave the lactam (XI) $(15 \mathrm{mg})$ which crystallised from ethanol, mp 198-199 . Anal. Calcd. for $\mathrm{C}_{21} \mathrm{H}_{21} \mathrm{O}_{5} \mathrm{~N}$ : C, 68.56; H, 5.76; N, 3.81. Found: C, 68.40; H, 5.68; N, 3.72. IR $v_{\max }^{\mathrm{KBr}} 1640 \mathrm{~cm}^{-1}(\mathrm{CO})$; $\lambda_{\max }^{\text {EtoH }} 229,263$, and $333 \mathrm{~nm}(\varepsilon 24800,21100$, and 18400) NMR $\delta: 7.75,7.20,6.89,6.78$, and 6.70 (s, 4 arH and Olefinic $\mathrm{H}$ ), 3.95 and 3.90 (s, $4 \mathrm{OMe}$ ).

Acknowledgement We thank Professor S. Uyeo of this Faculty for his hearty encouragement and also Emeritus Professor M. Tomita, Kyoto University for the sample of ( \pm )-xylopinine. We thank Dr. T. Shingu for the NMR spectral measurement and Mr. A. Kato for the mass spectral measurement. 